\title{
SMALL SCALE LASER-TRIGGERED ELECTRICAL DISCHARGES AND THEIR APPLICATION TO CHARACTERIZATION OF PLASMA CHANNEL INDUCED BY LIGHT FILAMENTS
}

\author{
G. Tamošauskas, L. Šaulys, A. Dubietis, and A. Piskarskas \\ Department of Quantum Electronics, Vilnius University, Sauletekio 9, LT-01222 Vilnius, Lithuania \\ E-mail: audrius.dubietis@ff.vu.lt \\ Received 7 January 2005
}

\begin{abstract}
We experimentally investigate triggering and guiding of kilovolt electrical discharges in air over short (few centimetre) gaps triggered by means of $1 \mathrm{ps}$ light filaments at $527 \mathrm{~nm}$. A method of direct measurement of free electron density along the plasma channel is proposed.
\end{abstract}

Keywords: self-focusing, light filament, ionization, laser-triggered discharge

PACS: 42.65.Jx, 52.80.--S

\section{Introduction}

Since the first demonstration of laser-induced electrical discharge [1] control of laser-triggered lightning discharges for lightning protection has became a long pursued task holding a great potential for practical applications [2-4]. Instead of high-energy continuouswave lasers such as $\mathrm{CO}_{2}$, emitting in the far infrared, the ultrashort pulse lasers with much shorter wavelengths (from near-infrared to ultraviolet) have been proven to be more advantageous offering a possibility to obtain continuous long ionized channels from the light filaments $[5,6]$. It is well known that when a femtosecond laser pulse with power above the critical power for self-focusing propagates in the atmosphere, it forms a long white-light filament, which ionizes the molecules of air [7]. This ionized trail (narrow plasma channel) has been considered to be useful for triggering and guiding the electrical discharges [8]. A number of laboratory experiments had proven the validity of this approach [9-13], and guided megavolt discharges with spark lengths up to $3.8 \mathrm{~m} \mathrm{[14]} \mathrm{were} \mathrm{reported} \mathrm{to} \mathrm{date.}$

Physical processes underlying a laser-triggered discharge are basically understood $[12,15]$. A simple explanation is that the light filament by means of multiphoton ionization produces a short-lived (in the range of nanoseconds [16]) conducting plasma channel $[17,18]$ that serves as a precursor for discharge. In long gaps free electrons are then accelerated by the external electric field and start a local avalanche process - the ionization wave, called streamer. The avalanche zone expands towards the direction of the opposite electrode developing a self-sustained conducting path (leader). Once a contact between the electrodes is established, an electrical discharge occurs. However, plasma filament cannot trigger an electrical discharge by itself because of its short lifetime, and the electrical discharge (or breakdown) appears after a certain delay (ranging from nanosecond to microsecond time scale) with respect to the optical pulse. As follows from the model, the buildup time for electrical discharge is governed by transient processes (electron drift velocity and avalanche ionization [6]) to provide the critical electron density for a conducting channel.

Somewhat different scenario is proposed for discharges in small gaps, assuming a constant electron density produced by the laser pulse. The current circulating in the laser-induced plasma channel produces significant heating of a thin air column by the Joule effect, which in turn is followed by radial expansion of the heated volume, and air depression meets the conditions providing a path for a guided discharge [13].

The number of free electrons in air under atmospheric pressure in normal conditions is usually very low (estimated to be less than $10^{3} \mathrm{~cm}^{-3}$ [19]) as compared with the atmospheric molecular density of $3 \cdot 10^{19} \mathrm{~cm}^{-3}$, therefore, if external electric field is applied, build-up time for a spontaneous discharge is long and typically requires a strength of external electric 
field of $25-30 \mathrm{kV} / \mathrm{cm}$. The situation becomes completely different if an ionized channel is created by the laser pulse. The build-up time as well as the voltage for electrical discharge are substantially reduced. Considering the above mechanism, it is clear then that the creation of free electrons is a necessary condition for a triggered discharge. Several methods to detect free electron density along the plasma channel were suggested. The simplest one is to measure the change of air resistance between the two electrodes after passage of the optical pulse [13] or to detect the free charges by capacitive coupling to a pick-up capacitor [18]. More complex methods include detection of electromagnetic radiation [20], backward emission [21], and detection of the sound waves emitted from an expanding plasma channel [22]. More recently, most of these methods were compared in multiparameter characterization of longitudinal plasma profile [23].

In this paper we report simple laboratory experiments on triggering and guiding of kilovolt electrical discharges by picosecond light filaments. We show that laser-triggered electrical discharge over small gaps could be potentially useful for estimation of free electron density distribution along the plasma channel, produced by an ionizing light filament.

\section{Experiment}

Recently, some of the present authors have observed several metre long white light filaments in air, induced by picosecond laser pulses in the visible spectral range [24]. In the experiment described in this paper, we have used a similar set-up for filament excitation, just with stronger focusing of an initial laser beam that results in shorter filament length. A 1 ps laser pulse at $527 \mathrm{~nm}$ with an energy of $2.35 \mathrm{~mJ}$ was produced by frequency doubling of commercial Nd:glass laser system output (TWINKLE, Light Conversion Ltd., Lithuania). The second harmonic beam with the initial FWHM diameter of $3.4 \mathrm{~mm}$ was focused in air by a $f=1 \mathrm{~m}$ lens producing several tenths of centimetres long light filament with a constant FWHM diameter of $\sim 50 \mu \mathrm{m}$.

Electrical part of the set-up consisted of two stainless steal disk electrodes with $2 \mathrm{~mm}$ holes and connected to high voltage supply with adjustable voltage between 3 and $24 \mathrm{kV}$. One of the electrodes was placed on a translation stage that allowed fine adjustment of the gap between the electrodes. The whole compartment was mounted on a long mechanical delay line allowing movement along the light path (Fig. 1).

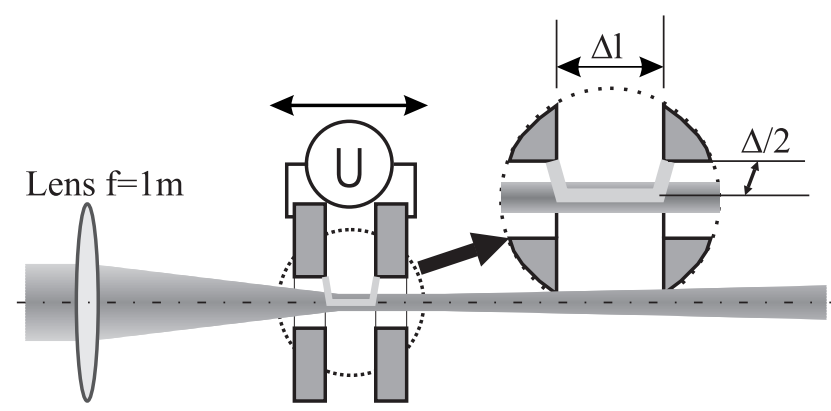

Fig. 1. Experimental set-up. Inset shows the geometry of electrical spark.

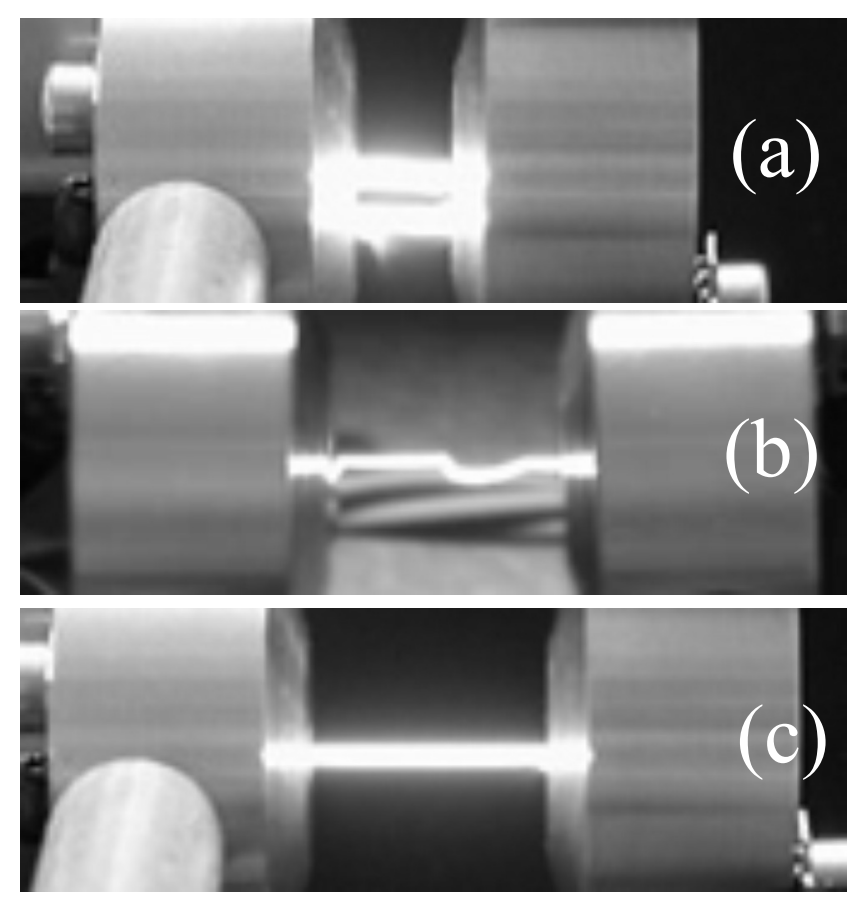

Fig. 2. Electrical discharge in air: (a) spontaneous discharge, seen as several sparks at random positions, $U=17 \mathrm{kV}$; (b) short filament induced discharge; the filament length is shorter than the gap between the electrodes, $U=20 \mathrm{kV}$; and (c) laser-triggered and guided $24 \mathrm{~mm}$ long spark, $U=23 \mathrm{kV}$.

Figure 2 illustrates three relevant cases of the observed electrical discharge. In the first case, Fig. 2(a), no optical pulse is present, and the electrical discharge starts spontaneously at random positions due to breakdown of the air (photocamera catched several sparks because of long exposure time). We have measured that the minimum voltage required for spontaneous discharge within the electrode gap of $5 \mathrm{~mm}$ is $17 \mathrm{kV}$. That gives a value for the dielectric breakdown of air of $34.0 \mathrm{kV} / \mathrm{cm}$, which is fairly consistent with that for the small gaps given in the literature [6]. The second case illustrates triggering of the electrical discharge by means of tightly focused ( $f=+300 \mathrm{~mm}$ ) laser beam 
that creates local optical breakdown of the air near the beam focus. In the breakdown region, the molecules of air are strongly ionized and give way to guiding of the electrical discharge over a short distance (half a gap between the electrodes). However, outside the ionized region, the guiding path is lost, and the electrical discharge ends up spontaneously with a position varying from shot to shot (Fig. 2(b)). In the third case, the electrical discharge is fully triggered and guided by the optical beam, that creates $\sim 10 \mathrm{~cm}$ long filament of a $50 \mu \mathrm{m}$ FWHM diameter, see Fig. 4(a). In the absence of the laser pulse, the distance between the electrodes $\Delta l=23 \mathrm{~mm}$ is too large for spontaneous discharge with $24 \mathrm{kV}$ voltage applied. However, in the presence of the optical pulse, that forms a filament, which ionizes the molecules of air, electrical discharge appears in the form of a straight line along the beam path (Fig. 2(c)). Under those settings, the value for dielectric breakdown of the air drops down significantly, to $10.4 \mathrm{kV} / \mathrm{cm}$. We have measured that the voltage for guided discharge grows linearly with increasing the gap between the electrodes (data not shown) according to the law:

$$
U=U_{L}(\Delta l+\Delta),
$$

where $U_{L}=8.25 \mathrm{kV} / \mathrm{cm}, \Delta l$ is the electrode gap, and $\Delta=2.5 \mathrm{~mm}$ is an additional distance set by the discharge geometry, see inset of Fig. 1.

It was reported in some previous experiments that the time delay between the optical pulse and the electrical discharge is reduced increasing either the laser intensity or the applied voltage [6]. This result is quite obvious, considering that the laser pulse of higher energy produces higher electron density, and the higher external electric field accelerates charges more to start the discharge process. The latter case was examined in our experiment by measuring time delay between the optical pulse and the optical emission from the electrical discharge (spark light), that was recorded by a fast photodiode connected to a digital oscilloscope (Tektronix, TDS 3032 with $300 \mathrm{MHz}$ bandwidth) triggered by an optical pulse. In these measurements, the geometrical position of the focal plane was aligned to be right in the middle between the electrodes. An exponential trend was measured for a wide range of applied voltages, see Fig. 3, and was found to follow the empirical expression

$$
\Delta t=2.48 \exp \left(\frac{\Delta l+\Delta}{0.22 U}\right)
$$

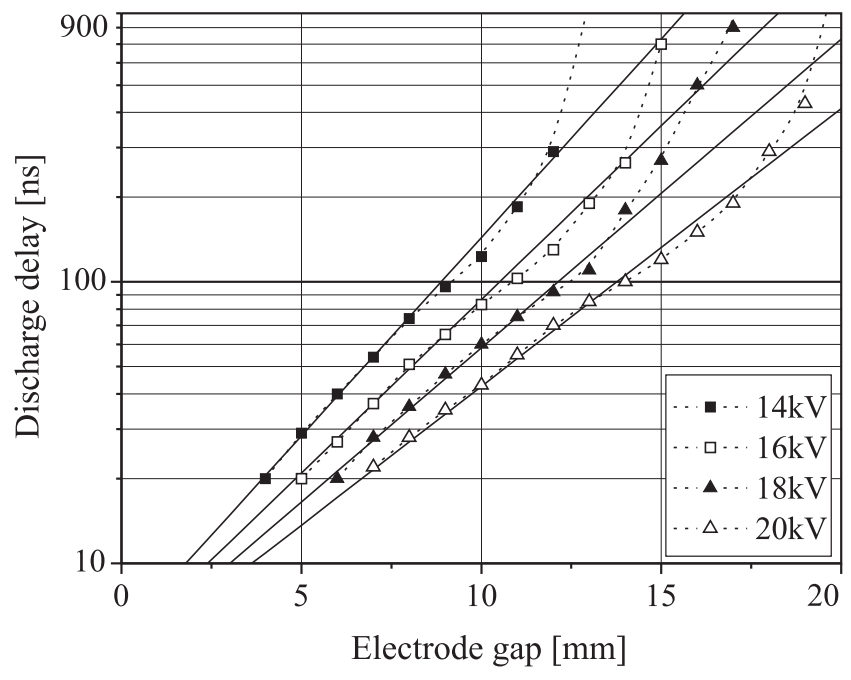

Fig. 3. Delay between the optical pulse and the laser-triggered discharge as a function of the applied voltage and electrode gap. Solid lines show the exponential fits as derived from Eq. (2), while dashed lines show the measured trend.

where $\Delta t$ is expressed in nanoseconds, $\Delta l$ and $\Delta$ in millimetres, and $U$ in kilovolts, respectively.

And finally, we have measured the voltage for a laser-triggered discharge by moving the electrical compartment along the beam path (see the summary of results depicted in Fig. 4).

The beam diameter was measured by inserting a movable fused silica plate into the beam path at $45^{\circ}$ incidence. A weak reflection from the plate was sent onto a 10-bit dynamic range CCD camera (COHU with Spiricon frame grabber). FWHM radius of the beam was estimated from the magnified single-shot images of the beam intensity profile (because of the optical damage that occurs due to very high intensity, each laser shot was reflected from a fresh region of the plate surface).

In the presence of the laser pulse, voltage required for triggering an electrical discharge drops down notably, with a minimum value of $7 \mathrm{kV}$ around the focal plane. From the measurement of the beam profile, we estimated the filament length to be $\sim 10 \mathrm{~cm}$ (Fig. 4(a)), whereas the area of reduced voltage extends before and far beyond the geometrical beam focus. This finding could be explained that even outside the filamentary zone the laser intensity is still sufficient to ionize the molecules of air. Indeed, earlier observations indicate that free electron density of $10^{11}$ $10^{12} \mathrm{~cm}^{-3}$ is still enough for triggering and guiding the electrical discharge [10]. It has to be noted that in our measurement the time delay between the optical pulse and the electric discharge varied much - from 


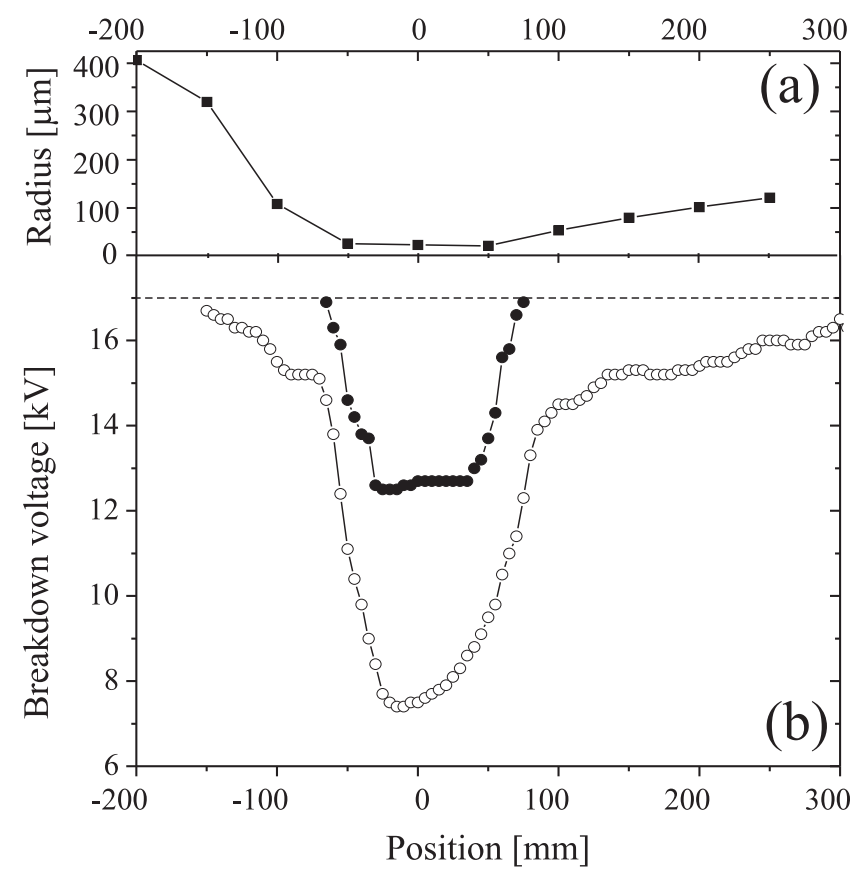

Fig. 4. (a) FWHM beam radius and (b) breakdown voltage as functions of the longitudinal coordinate. 0 denotes the geometrical focus of the lens. Open circles show the minimum voltage for guided discharge with a fixed electrode gap $\Delta l=5 \mathrm{~mm}$, while full circles denote the voltage for guided discharge with $\Delta l=5 \mathrm{~mm}$ and fixed delay time $\Delta t=50 \mathrm{~ns}$. Dashed line at $U=17 \mathrm{kV}$ denotes the voltage for a spontaneous discharge.

$200 \mathrm{~ns}$ to several $\mu$ s depending on the applied voltage and the position relative to the lens focal plane. We repeated the measurement setting a fixed delay time of $\Delta t=50 \mathrm{~ns}$, as shown by full circles in Fig. 4(b). A fixed delay time, in this case, means that all the transient processes leading to electrical discharge are "equalized" from one measurement to another while moving along the beam path. Then the voltage curve exhibited an extended plateau at $U=12.5 \mathrm{kV}$ over $10 \mathrm{~cm}$, that actually coincides with a constant filament diameter of $50 \mu \mathrm{m}$, see an apparent correlation between these two as shown in Fig. 4. Our measurement shows that uniform plasma channels may be induced by light filamentation due to the so-called intensity clamping effect [25]. Assuming that the relation between the free electron density and the high-voltage threshold for laser-induced discharge is linear [6], we consider that the measurement of discharge voltage along the filament with a fixed delay time directly reflects the free electron density along the beam path. The proposed method, however, needs to be further elaborated extracting the real values of the free electron density.

\section{Conclusions}

In conclusion, we have demonstrated a simple setup for triggering and guiding of kilovolt electrical discharges in air by means of picosecond light filaments induced by the self-focusing effect. Under our operating conditions and capabilities of the electrical setup, we trigger and guide a $24 \mathrm{kV}$ electrical discharge over a $23 \mathrm{~mm}$ gap. We have shown experimentally that in the presence of an ionizing light filament the electrical breakdown voltage of air is significantly reduced (from $34 \mathrm{kV} / \mathrm{cm}$ down to $10.4 \mathrm{kV} / \mathrm{cm}$ ) in the short-gap geometry. Laser-triggered discharge timing measurements revealed an exponential dependence of the delay time between the laser pulse and the laser-triggered electrical discharge on the electrode gap for short buildup times. And finally, we have demonstrated that lasertriggered discharge over small gaps might be potentially useful for the measurement and determination of the free electron density along the ionizing light filament.

\section{References}

[1] D.W. Koopman and T.D. Wilkerson, Channeling of an ionizing electrical streamer by a laser beam, J. Appl. Phys. 42, 1883-1886 (1971).

[2] X.M. Zhao, J.-C. Diels, C.Y. Wang, and J.M. Elizondo, Femtosecond ultraviolet laser pulse induced lightning discharges in gasses, IEEE J. Quantum Electron. 31, 599-612 (1995).

[3] S. Uchida, Y. Shimada, H. Yasuda, S. Motokoshi, C. Yamanaka, T. Yamanaka, Z. Kawasaki, and K. Tsubakimoto, Laser-triggered lightning in field experiments, J. Opt. Technol. 66, 199-202 (1999).

[4] N. Khan, N. Mariun, I. Aris, and J. Yeak, Laser triggered lightning discharge, New J. Phys. 4, 61.1-20 (2002).

[5] B. La Fontaine, F. Vidal, Z. Jiang, C.Y. Chien, D. Comtois, A. Desparois, T.W. Johnston, J.-C. Kiefer, H. Pépin, and H.P. Mercure, Filamentation of ultrashort pulse laser beams resulting from their propagation over long distances in air, Phys. Plasmas 6, 16151621 (1999).

[6] P. Rambo, J. Schwarz, and J.-C. Diels, High-voltage electrical discharges induced by an ultrashort-pulse UV laser system, J. Opt. A 3, 146-158 (2001).

[7] A. Braun, G. Korn, X. Liu, D. Du, J. Squier, and G. Mourou, Self channeling of high-peak-power femtosecond laser pulses in air, Opt. Lett. 20, 73-75 (1995). 
[8] B. La Fontaine, F. Vidal, D. Comtois, C.-Y. Chien, A. Desparois, T.W. Johnston, J.-C. Kieffer, H.P. Mercure, H. Pépin, and F.A.M. Rizk, The influence of electron density on the formation of streamers in electrical discharges triggered with ultrashort laser pulses, IEEE Trans. Plasma Sci. 27, 688-700 (1999).

[9] P. Rambo, J. Biegert, V. Kubecek, J. Schwarz, A. Bernstein, J.-C. Diels, R. Bernstein, and K. Stahlkopf, Laboratory tests of laser-induced lightning discharge, J. Opt. Technol. 66, 194-198 (1999).

[10] B. La Fontaine, D. Comtois, C.-Y. Chien, A. Desparois, F. Genin, G. Jarry, T. Johnston, J.-C. Kiefer, F. Martin, R. Mawassi, H. Pépin, F.A.M. Rizk, F. Vidal, C. Potvin, P. Couture, and H.P. Mercure, Guiding large-scale spark discharges with ultrashort pulse laser filaments, J. Appl. Phys. 88, 610-615 (2000).

[11] D. Comtois, C.Y. Chien, A. Desparois, F. Genin, G. Jarry, T.W. Johnston, J.C. Kiefer, B. La Fontaine, F. Martin, R. Mawassi, H. Pépin, F.A.M. Rizk, and F. Vidal, Trigerring and guiding leader discharges using plasma channel created by an ultrashort laser pulse, Appl. Phys. Lett. 76, 819-821 (2000).

[12] H. Pépin, D. Comtois, F. Vidal, C.Y. Chien, A. Desparois, T.W. Johnston, J.-C. Kieffer, B. La Fontaine, F. Martin, F.A.M. Rizk, C. Potvin, P. Couture, H.P. Mercure, A. Bondiou-Clergerie, P. Lalande, and I. Gallimberti, Triggering and guiding high-voltage large-scale leader discharges with sub-joule ultrashort laser pulses, Phys. Plasmas 8, 2532-2539 (2001).

[13] S. Tzortzakis, B. Prade, M. Franco, A. Mysyrowicz, S. Huller, and P. Mora, Femtosecond laser-guided electric discharge in air, Phys. Rev. E 64, 057401 (2001).

[14] M. Rodriguez, R. Sauerbrey, H. Wille, L. Wöste, T. Fujii, Y.-B. André, A. Mysyrowicz, L. Klingbeil, K. Rethmeier, W. Kalkner, J. Kasparian, E. Salmon, J. Yu, and J.-P. Wolf, Triggering and guiding megavolt discharges using laser-induced ionized filaments, Opt. Lett. 27, 772-774 (2002).

[15] A. Bondiou and I. Gallimberti, Theoretical modelling of the development of the positive spark in long gaps, J. Phys. D 27, 1252-1266 (1994).
[16] S. Tzortzakis, B. Prade, M. Franco, and A. Mysyrowicz, Time-evolution of the plasma channel at the trail of a self-guided IR femtosecond laser pulse in air, Opt. Commun. 181, 123-127 (2000).

[17] S. Tzortzakis, M.A. Franco, Y.-B. André, A. Chiron, B. Lamouroux, B.S. Prade, and A. Mysyrowicz, Formation of a conducting channel in air by self-guided femtosecond laser pulses, Phys. Rev. E 60, R3505R3507 (1999).

[18] H. Schillinger and R. Sauerbrey, Electrical conductivity of long plasma channels in air generated by selfguided femtosecond laser pulses, Appl. Phys. B 68, 753-756 (1999).

[19] J. Chen and J.H. Davidson, Electron density and energy distributions in the positive DC corona: Interpretation for corona-enhanced chemical reactions, Plasma Chem. Plasma Process. 22, 199-224 (2001).

[20] S.A. Hosseini, B. Ferland, and S.L. Chin, Measurement of filament length generated by an intense femtosecond laser pulse using electromagnetic radiation detection, Appl. Phys. B 76, 583-586 (2003).

[21] S.A. Hosseini, Q. Luo, B. Ferland, W. Liu, N. Aközbek, G. Roy, and S.L. Chin, Effective length of filaments measurement using backscattered fluorescence from nitrogen molecules, Appl. Phys. B 77, 697-702 (2003).

[22] J. Yu, D. Mondelain, J. Kasparian, E. Salmon, S. Geffroy, C. Favre, V. Boutou, and J.P. Wolf, Sonographic probing of laser filaments in air, Appl. Opt. 42, 71177120 (2003).

[23] S.A. Hosseini, J. Yu, Q. Luo, and S.L. Chin, Multiparameter characterization of the longitudinal plasma profile of a filament: A comparative study, Appl. Phys. B 79, 519-523 (2004).

[24] D. Mikalauskas, A. Dubietis, and R. Danielius, Observation of light filaments induced in air by visible picosecond laser pulses, Appl. Phys. B 75, 899-902 (2002).

[25] W. Liu, S. Petit, A. Becker, N. Aközbek, C.M. Bowden, and S. L. Chin, Intensity clamping of a femtosecond laser pulse in condensed matter, Opt. Commun. 202, 189-197 (2002). 


\title{
MAŽŲ MATMENŲ LAZERIU SUKELTI ELEKTROS IŠLYDŽIAI IR JU TAIKYMAS ŠVIESOS GIJU SUKURIAMIEMS PLAZMOS KANALAMS APIBŪDINTI
}

\author{
G. Tamošauskas, L. Šaulys, A. Dubietis, A. Piskarskas
}

Vilniaus universitetas, Vilnius, Lietuva

\section{Santrauka}

Eksperimentiškai tirti mažo atstumo kilovoltiniai elektros išlydžiai ore, sužadinami ir valdomi pikosekundinemis šviesos gijo- mis. Pasiūlytas tiesioginis metodas, kaip, taikant šviesa indukuotus elektros išlydžius, galima nustatyti laisvuju elektronų, sukuriamu šviesos gijai sklindant ore, tankị išilgai sklidimo krypties. 